\title{
Global atmospheric change and human health: an integrated modelling approach
}

\author{
W. J. M. Martens \\ University of Limburg, Department of Mathematics, PO Box 616, 6200 MD Maastricht, The Netherlands
}

\begin{abstract}
Only recently has attention been paid to the possible consequences of global environmental problems for human health. There is still much to be learned about the potential health effect of global environmental changes. Major phenomena that can be expected to have a significant health effect include climate change, ozone depletion and air pollution. Currently, the health impacts of such global atmospheric changes are being investigated separately although in many instances interactions are possible if not probable. Examining the health impact of global environmental problems by dividing them into components may well be a useful approach to analyzing the contribution of the various impacts. However, if these problems are to be analyzed comprehensively, and where responses need to be developed, a holistic approach would seem to be the most promising.
\end{abstract}

KEY WORDS: Human health - Risk factors - Simulation model

\section{INTRODUCTION}

Broadly speaking, the various potential effects of global climate change upon human health can be divided into direct and indirect effects, and the latter will be discussed first (Table 1). One of the potentially major indirect impacts of global climate change upon human health could occur via effects upon cereal crop production (Parry \& Rosenzweig 1993). Cereal grains

Table 1. Some major potential health effects of global atmospheric change

\begin{tabular}{|ll|}
\hline Phenomenon & \multicolumn{1}{c|}{ Health impact } \\
Climate & $\begin{array}{l}\text { Heat-related diseases and disorders } \\
\text { Altered distribution of vector-borne diseases } \\
\text { Effects on food production } \\
\text { Sea-level rise } \\
\text { Effects on fresh water supply }\end{array}$ \\
Ozone $\left(\mathrm{O}_{3}\right)$ & $\begin{array}{l}\text { Skin cancers } \\
\text { depletion }\end{array}$ \\
& $\begin{array}{l}\text { Cataracts } \\
\text { Suppression of immunity }\end{array}$ \\
& Effects on food production \\
Air & Respiratory diseases \\
pollution & Heart stress \\
& Suppression of immunity \\
\hline
\end{tabular}

account for around two-thirds of all food stuffs consumed by humans. These impacts would occur via the effects of variations in temperature and moisture upon germination, growth, and photosynthesis, as well as via indirect effects upon plant diseases, predator-pest relationships, and supplies of irrigation water. Tropical regions are likely to be the most adversely affected, and, in such increasingly populous and often poor countries, any decline in agricultural productivity during the next century could have significant public health consequences. A further important indirect effect on human health may well prove to be the (re-jintroduction of vector-borne diseases. Temperature and precipitation changes might influence the behavior and geographical distribution of vectors, and thus change the incidence of vector-borne diseases which are major causes of morbidity and mortality in most tropical countries (Martens et al. 1994, 1996).

To turn now to direct health effects, a small increase in the average temperature would mean that there would be more days each year during which a certain threshold temperature would be exceeded. Above this threshold temperature, human heat regulatory mechanisms cannot cope with further increases in ambient temperature. If temperature exceeds this threshold value, especially over a period of several days, total mortality increases substantially (Kalkstein \& Smoyer 
1993). The most direct impact of heat stress on the human body is the onset of heat exhaustion or heatstroke (Kilbourne 1992). Nevertheless, hot weather is associated with mortality resulting from a variety of causes, for instance deaths from cardiovascular and respiratory disorders (Larsen 1990).

If a long-term increase of UVB radiation due to stratospheric ozone depletion occurs, melanoma and non-melanoma skin cancer will increase, people with lightly pigmented skins being most susceptible. The incidence of various diseases of the eye, particularly pterygium and cataract, is also likely to increase (UNEP 1991). There is less certainty about whether damage to the human immune system (both local and systemic) may occur. A potentially more important, indirect effect of increased UVB levels reaching the Earth could be the UV-induced impairment of photosynthesis on land (food crops) and in the sea (phytoplankton), reducing the world's food production (WHO 1994).

The 5 main air pollutants of concern in urban environments are sulfur dioxide $\left(\mathrm{SO}_{2}\right)$, the nitrogen oxides $\left(\mathrm{NO}_{X}\right)$, carbon monoxide $(\mathrm{CO})$, ozone $\left(\mathrm{O}_{3}\right)$ and suspended particulate matter (including lead, Pb). Sulfur compounds, particulates, $\mathrm{O}_{3}$ and $\mathrm{N}_{2} \mathrm{O}$ all impair pulmonary function and increase morbidity and mortality, especially in sufferers from chronic obstructive pulmonary diseases (COPD). Carbon monoxide reduces the oxygen-carrying capacity of the blood, causing increased morbidity and mortality, especially in people with chronic cardiac diseases. A further health effect traceable to these major air pollutants is an altered immune defense (WHO 1987).

The potential impacts of climate change, $\mathrm{O}_{3}$ depletion and air pollution have been discussed as if they were separate phenomena. However, from the above discussion, it is clear that global atmospheric changes will jointly impact human health. Furthermore, one cannot separate the possible adverse health effects of anthropogenically induced atmospheric changes. These effects are very likely to be synergistic and may be cumulative in vulnerable populations, which is illustrated by the following issues.

The paramount health problem in the world appears to be that of nutrition and infectious diseases and their interrelationships: malnutrition may exacerbate risks of morbidity and mortality and the increased prevalence of infectious disease is thought to increase malnutrition. An anthropogenic climate change is likely to influence both.

The interaction between climate and air pollution remains a subject of scientific debate. Some studies have found climate factors to be less important than air pollution in terms of impact on mortality (e.g. Schwartz \& Marcus 1990, Dockery et al. 1993). Other studies point to weather conditions as the primary environmental factor affecting mortality (e.g. Kalkstein 1993) In any case, weather and air pollution both influence mortality levels, and especially affect children and old people.

The human immune system is likely to be adversely affected by both increased UVB radiation and air pollution levels. This would reduce protection against infectious and fungal diseases, and could reduce vaccination efficiency in immunologically marginal (i.e. undernourished and chronically infected) populations, the same populations which are likely to be most affected by climate change induced reductions in agricultural production and the gradual (re-)appearance of infectious diseases.

The prevalence of cataracts is often much higher among elderly, malnourished persons in poor countries, where micronutrient deficiency may contribute to cataract formation (Harding 1992). Thus, besides being an effect of increasing UVB levels, cataract prevalence may be influenced by a change in the availability of food.

Although there are presumably other, synergistic health impacts associated with global atmospheric change which we have not yet foreseen, and others beyond the scope of this report, the examples given above suffice to illustrate the need for the development of an integrated framework by means of which to understand the human health impacts which global anticipated atmospheric changes imply.

The objectives of this report are to summarize potential impacts of global climate change on human health, and to present an integrated systems approach for assessing human health impacts associated with global environmental change.

\section{METHODS}

One of the main lessons which has hitherto been learned in environmental health research is that, broadly speaking, the reductionist approach based on aspect compartment-oriented research methods has failed to generate a methodology which is adequate for analyzing complex, multidisciplinary, large-scale global phenomena. A more promising approach would seem to be a holistic, integrated approach, based on a systems-oriented analysis, which concentrates on the interactions between the different subsystems of cause-effect chains rather than focusing on each subsystem in isolation (Dzidonu \& Foster 1993). Given the complexity of the health-impactive phenomena at issue here, and the relative ignorance about the basic processes and interactions that determine their dynamics, the systems approach can help to foster 


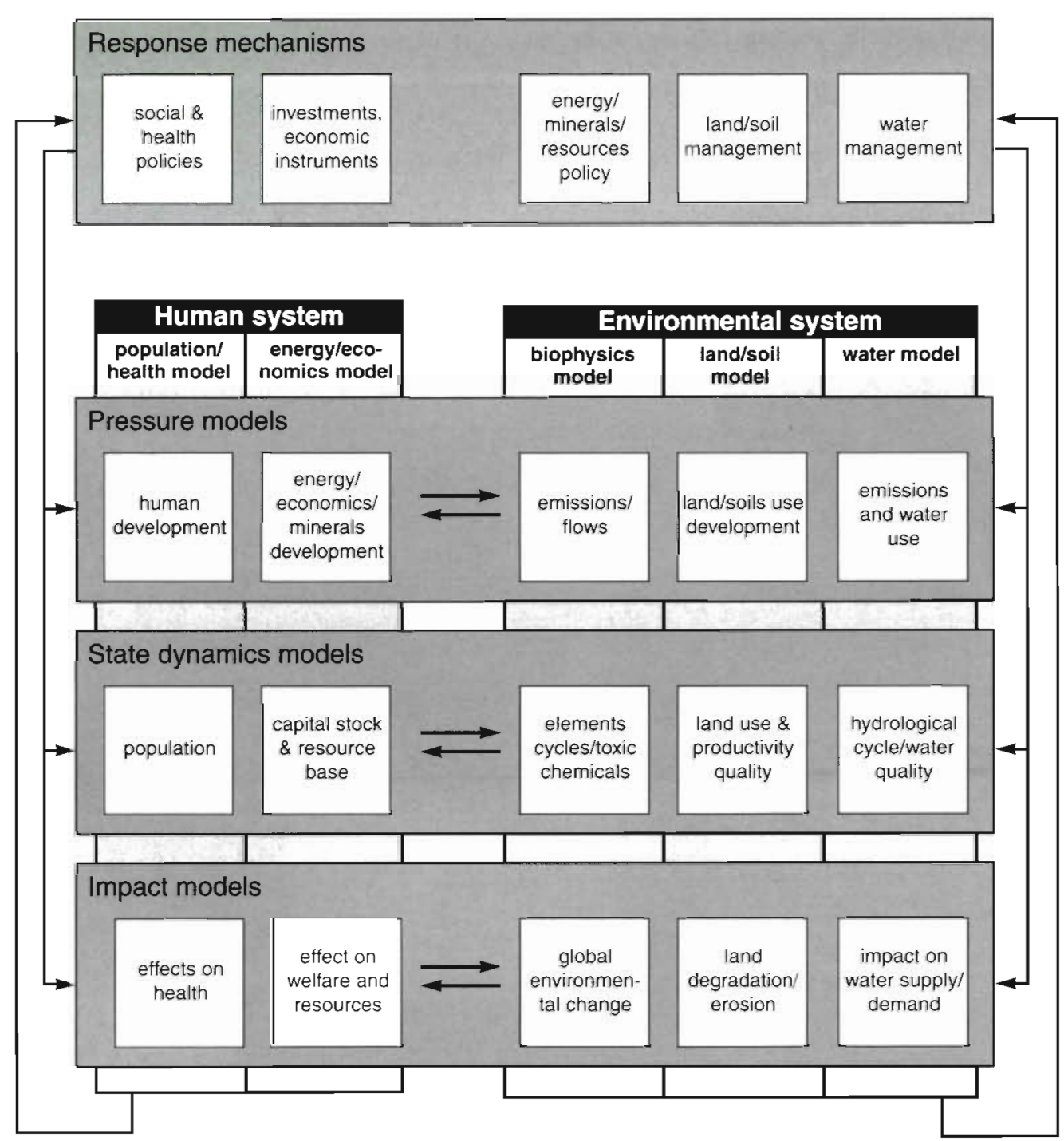

Fig. 1. Modular perspective of TARGETS, version 1.0

understanding of the causal relationships that are responsible for changes in the structure and dynamics of the system.

The conceptual model. The integrated assessment modelling framework for global atmospheric changes and human population health, accounting for interregional variations in vulnerabilities of populations and variations in magnitude of effects, has been named MIASMA ${ }^{1}$ (Model for the health Impact ASsessment of Man-induced Atmospheric changes). As the issue is inextricably related to socioeconomic, demographic and other environmental changes, MIASMA is part of the modelling framework that is being developed by the interdisciplinary program 'Global Dynamics and Sustainable Development' of the National Institute of Public Health and Environmental Protection (RIVM) in The Netherlands. The overall modelling framework is the TARGETS model (see Fig. 1), which is designed to operationalize the concept of sustainable development on a global scale (for more detailed information see Niessen \& Rotmans 1993, Rotmans et al. 1994). An outline of the prototype of MIASMA in conceptual terms is illustrated in Fig. 2.

The aim of this specific part of TARGETS is to simulate changes in morbidity and mortality levels under

\footnotetext{
${ }^{1}$ Miasma is a word derived from the Greek meaning: to pollute. An antique theory asserted that gases which rose from the soil, especially when high temperatures caused decomposition and decay to take place, contained 'miasma', a substance causing diseases and epidemics. Although the miasmatic theory was abandoned long ago, it is an irony of history that state-of-the-art environmental health science is now striving to quantify the relationship between atmospheric conditions and the incidence of diseases
} 


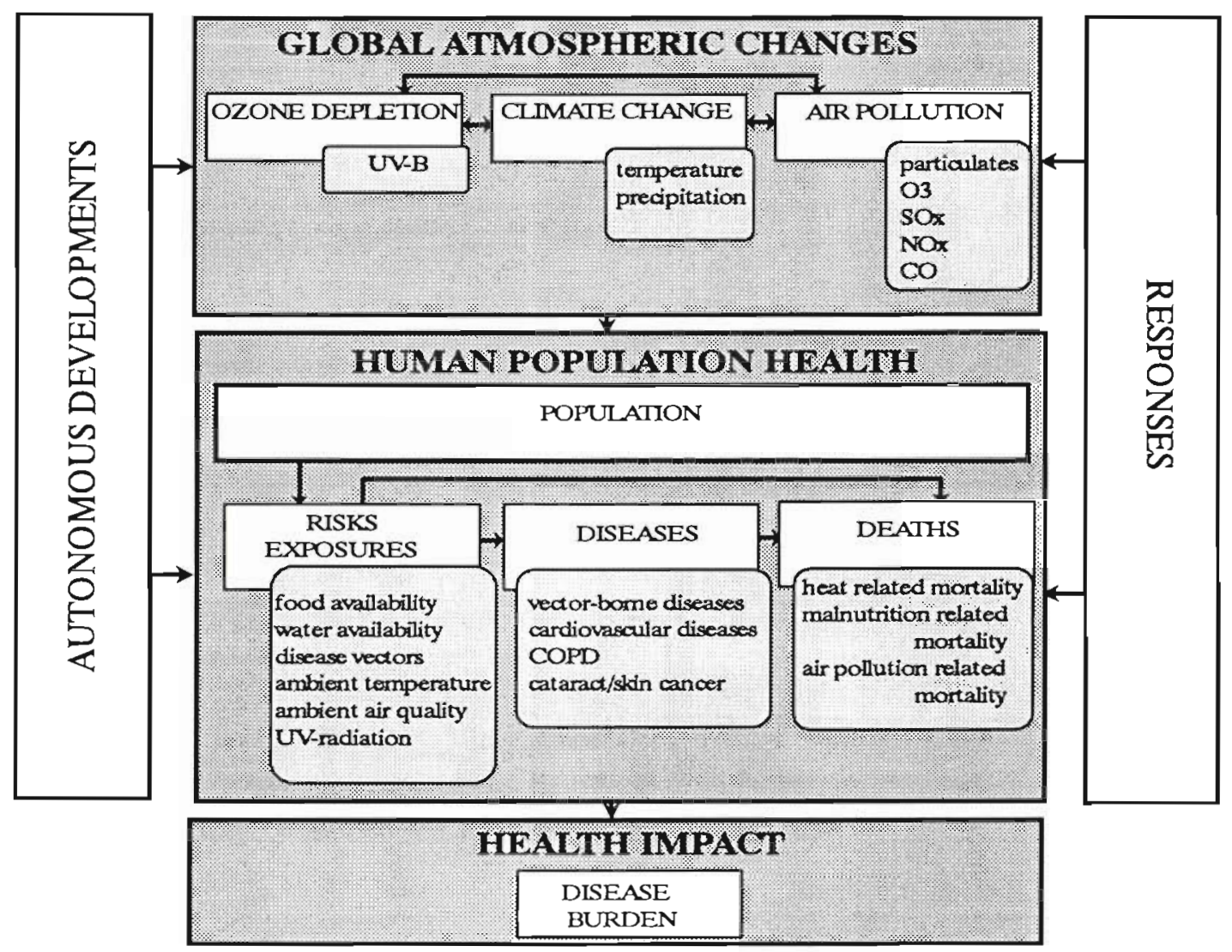

Fig 2 Conceptual representation of the Model for the health Impact ASsessment of Man-induced Atmospheric changes (MIASMA)

varyung socio-economic, demographic and, most importantly, environmental conditions: MIASMA is designed to describe the major cause and effect relationships between atmospheric changes and human population health. It includes an environmental subsystem and a human subsystem. The environmental subsystem comprises a global elements cycles module, a climate assessment module and an ozone assessment module (Den Elzen 1993) Global atmospheric changes influence the exposure to health risks directly, via changes in ambient temperature and air quality and received UVB radiation, as well as indirectly, in changing food and clean water avalability and influencing the prevalence and distribution of vector-borne diseases (e.g malaria and schistosomasıs). Changes in the pattern of health determinants (risk exposure subsystem) demarcate the changes in the levels of incldence for the diseases influenced by the determinants. To determine the level of incidence of diseases, those who have actually falien lli are moved to the reservour for the specific diseases concerned. According to the disease-specific modules (Manton \& Stallard 1988 and Weinstein 1989 for chronic diseases; Anderson \& May 1991 for infectious diseases) a certain fraction of the diseased population dies. The mortality rates associated with cardiovascular and respiratory diseases are directly influenced by levels of air pollution and heat stress, mainly in urban areas. Malnourished populatrons are subject to an excess risk of deaths due to fralty of physical condition (Pelletier et al. 1993).

The transition probabilities of moving from one reservolr to the other (moving from the non-exposed to the exposed population and vice versa, moving from the exposed to the diseased population and vice versa, and simply dying) do not only depend on global atmospherac changes as described above, but also on age, sex, type of exposure and disease status. Socio-economic development affects prevention (water supply and sanitation and vector control) and treatment (therapeutic competence) of diseases, and therefore meaningfully changes the potency of determinants. The health umpact of global atmospheric changes is in general directly related to the severity of the diseases affected, measured in terms of disability and death. These effects can be quantified in terms of the number of years of healthy life lost. The concept of a disabilityadjusted life year (DALY) (Murray 1994) is therefore used as a measure of the change in disease burden in 
human populations which can be associated with atmospheric changes.

Model applications. MIASMA has been developed for the global scale, with a time horizon of $130 \mathrm{yr}$ starting in 1970, and running in time steps of 1 yr till the year 2100. Two important issues in the development of the model are a flexible integrated methodology to allow for flexible inclusion of various sets of determinants and disease specific sub-models as well as the collection of global and regional data for validation. Later versions of the model are planned which will be disaggregated to the level of world regions or countries. The strength of MIASMA lies in the integration and interfacing of a large number of models drawn from a variety of disciplines. In general, essential processes are exclusively described in meta models, although the overall design allows for the inclusion of more complex models. The modelling approach is holistic in that it is orientated towards integrating, both vertically and horizontally, various global atmospheric disturbances and their respective health effects. Vertically the model is designed to cover as much as possible of the cause-effect relationship with respect to global atmospheric changes and human health; horizontally, the model is able to integrate the various health impacts. Despite the many advantages of the integrated systems approach, a disadvantage is the sequence of uncertainties introduced by the linkage of separate models: the uncertainty range widens as one moves to more remote links in the cause-effect chain. On the other hand, an integrated assessment model such as MIASMA enables comparison of the relative importance of these uncertainties (McMichael \& Martens 1995). In our view, the interpretative and illustrative value of MIASMA is much more important than its predictive potency.

\section{DISCUSSION}

A major task for science which investigates public health issues is to provide policymakers and their public constituency with a clearer description of the anticipated future health impacts of global environmental change (Last 1993, McMichael 1993). The integrated systems and modelling approach introduced here enables the health consequences of several types of global environmental changes to be evaluated simultaneously. Moreover, synergistic health effects which are currently beyond the horizon of predictive competence may be brought into view. Such a global integrated assessment model should be regarded as an aid to the formulation of possible projections for the future, and not as a means of generating predictions as such. However, the provision of information to decisionmakers is crucial, and, insofar as addressing future health impacts of global environmental changes is concerned, a holistic integrated mathematical modelling approach is the best available tool in scientific assessment (O'Riordan \& Rayner 1991) The model will also yield insights into the mediating processes within the complex system being modelled. These, and the projected outcomes, can assist in the development of adaptive and preventive strategies

\section{LITERATURE CITED}

Anderson RM, May RM (1991) Infectious diseases of humans: dynamics and control. Oxford University Press, New York

Den Elzen MGJ (1993) Global environmental change: an integrated modelling approach. International Books, Utrecht

Dockery DW et al. (1993) An association between air pollution and mortality in six U.S. cities. N Engl J Med 329(24) 1753-1759

Dzidonu CK, Foster FG (1993) Prolegomena to OR modelling of the global environment-development problem. J Operational Res Soc 44(4):321-331

Harding JJ (1992) Physiology, biochemistry, pathogenesis, and epidemiology of cataract. Curr Opin Ophthalmol 3: 3-12

Kalkstein LS (1993) Health and climate change: direct impacts in cities. Lancet 342:1397-1399

Kalkstein LS, Smoyer KE (1993) The impact of climate change on human health: some international implications. Experientia 49:969-979

Kilbourne EM (1992) Illness due to thermal extremes. In: Last $J M$, Wallace RB (eds) Public Health and preventive medicine, 13th edn. Appleton lange, Norwalk, CT, p 187-201

Larsen $U(1990)$ The effect of monthly temperature fluctuations on mortality in the United States from 1921 to 1985. Int J Biometeorol 34:136-145

Last JM (1993) Global change: ozone depletion, greenhouse warming and public health. Ann Rev Public Health 14 $115-36$

Manton KG, Stallard E (1988) Chronic disease modelling. Charles Griffin and Co. Ltd, London

Martens WJM, Rotmans J, Niessen LW (1994) Climate change and malaria risk: an integrated modelling approach. GLOBO Report Series no. 3, RIVM Report no. 46152003 Bilthoven

Martens WJM, Niessen LW, Rotmans J, Jetten TH, MCMichael AJ (1996) Potential impact of global climate change on malaria risk. Environ Health Perspect (in press)

MCMichael AJ (1993) Global environmental change and human population health: a conceptual and scientific challenge for epidemiology. Int J Epidemiol 22:1-8

McMichael AJ, Martens WJM (1995) The health impact of global climate change: grappling with scenarios, predictive models and multiple uncertainties. Ecosyst Health 1(1):15-25

Murray CJL (1994) Quantifying the burden of disease: the technical basis for disability adjusted life years. Bull WHO $72(3): 429-445$

Niessen LW, Rotmans J (1993) Sustaining health: towards an integrated global health model. GLOBO Report Series no. 1, RIVM Report no. 461502001, Bilthoven

O'Riordan T, Rayner S (1991) Risk management for global environmental change. Global Environ Change 3:91-108 
Parry ML, Rosenzweig C (1993) Food supply and the risk of hunger. Lancet 342:1284-1285

Pelletier DL, Frongillo EA, Habicht JP (1993) Epidemiological evidence for a potentiating effect of malnutrition on child mortality. Am J Public Health 83(8):1130-1133

Rotmans J et al. (1994) Global change and sustainable development: a modelling perspective for the next decade. GLOBO Report Series no. 4, RIVM Report no. 461502004, Bilthoven

Schwartz J, Marcus A (1990) Mortality and air-pollution in London: a time-series analysis. Am $J$ Epidemiol 131. $185-194$
United Nations Environment Programme (UNEP) (1991) Environmental effects of ozone depletion. 1991 update. UNEP. Nairobi

Weinstein MC (1989) Methodological issues in policy modelling for cardiovascular disease. J Am Coll Cardio 14: $38 \mathrm{~A}-43 \mathrm{~A}$

World Health Organization (WHO) (1987) Air quality guidelines for Europe. Regional Pub., European Series no. 23, WHO, Copenhagen

World Health Organization (WHO) (1994) Ultraviolet radiation. Environmental Health Criteria 160, World Health Organization, Geneva 